\title{
BMJ Open Functional visual fields: a cross-sectional UK study to determine which visual field paradigms best reflect difficulty with mobility function
}

\author{
Hikmat Subhi, ${ }^{1}$ Keziah Latham, ${ }^{1}$ Joy Myint, ${ }^{2}$ Michael Crossland ${ }^{3}$
}

To cite: Subhi H, Latham K, Myint J, et al. Functional visual fields: a cross-sectional UK study to determine which visual field paradigms best reflect difficulty with mobility function. BMJ Open 2017;7:e018831. doi:10.1136/ bmjopen-2017-018831

- Prepublication history for this paper is available online. To view these files, please visit the journal online (http://dx.doi.org/)

Received 25 July 2017 Revised 10 October 2017 Accepted 11 October 2017

CrossMark

${ }^{1}$ Department of Vision and Hearing Sciences, Anglia Ruskin University, Cambridge, UK ${ }^{2}$ University of Hertfordshire School of Life and Medical Sciences, Hatfield, UK

${ }^{3}$ Department of Optometry, Moorfields Eye Hospital NHS Foundation Trust, London, UK

Correspondence to

Hikmat Subhi;

hikmat.subhi@anglia.ac.uk

\section{ABSTRACT}

Objectives To develop an appropriate method of assessing visual field (VF) loss which reflects its functional consequences, this study aims to determine which method(s) of assessing VF best reflect mobility difficulty. Setting This cross-sectional observational study took place within a single primary care setting. Participants attended a single session at a University Eye Clinic, Cambridge, UK, with data collected by a single researcher (HS), a qualified optometrist.

Participants 50 adult participants with peripheral field impairment were recruited for this study. Individuals with conditions not primarily affecting peripheral visual function, such as macular degeneration, were excluded from the study.

Primary and secondary outcome measures Participants undertook three custom and one standard binocular VF tests assessing VF to $60^{\circ}$, and also integrated monocular threshold 24-2 visual fields (IVF). Primary VF outcomes were average mean threshold, percentage of stimuli seen and VF area. VF outcomes were compared with selfreported mobility function assessed with the Independent Mobility Questionnaire, and time taken and patient acceptability were also considered. Receiver operating characteristic (ROC) curves determined which tests best predicted difficulty with mobility tasks.

Results Greater VF loss was associated with greater self-reported mobility difficulty with all field paradigms $\left(R^{2} 0.38-0.48\right.$, all $\left.P<0.001\right)$. All four binocular tests were better than the IVF at predicting difficulty with at least three mobility tasks in ROC analysis. Mean duration of the tests ranged from $1 \mathrm{~min} 26 \mathrm{~s}( \pm 9 \mathrm{~s})$ for kinetic assessment to 9 min $23 \mathrm{~s}( \pm 24 \mathrm{~s})$ for IVF.

Conclusions The binocular VF tests extending to $60^{\circ}$ eccentricity all relate similarly to self-reported mobility function, and slightly better than integrated monocular VFs. A kinetic assessment of VF area is quicker than and as effective at predicting mobility function as static threshold assessment.

\section{INTRODUCTION}

Visual field (VF) loss is an extremely important dimension of visual impairment. There are significant consequences of VF loss for functional ability, ${ }^{1-6}$ including increased difficulty with mobility, ${ }^{7-12}$ and potentially

\section{Strengths and limitations of this study}

- Rigorous and novel visual field (VF) testing on a cohort of people with VF loss.

- Consideration of the patient's perspective of VF assessment.

- Use of Rasch analysed data from a validated questionnaire to reflect a broad range of mobility function.

- Different VF paradigms compared with functional vision, which has not previously been reported.

- Single, rather than repeated, measures of VF function are used.

also increased risk of falling ${ }^{11}{ }^{13-18}$ and of car accidents. ${ }^{19}$ However, currently available conventional $\mathrm{VF}$ tests are designed to detect and monitor the progression of disease, and are not optimised for reflecting the functional consequences of VF loss. Although binocular VF are known to be important in individuals with visual impairment, particularly $\mathrm{VF}$ beyond $30^{\circ},{ }^{20}$ conventional $\mathrm{VF}$ tests only measure monocular $\mathrm{VF}$ of the central $30^{\circ}$ or less. ${ }^{21-24}$

$\mathrm{VF}$ assessments are demanding procedures $^{25}$ and many people dislike performing VF tests. ${ }^{25}{ }^{26}$ An ideal functional field test would take into account the acceptability of tests to a patient, on the basis that an acceptable test and duration will provide better data. ${ }^{27}$ Patients' opinion of vision testing is largely unreported, although it has been suggested that this is due to difficulty objectively quantifying subjective or 'human factors', of field assessment. ${ }^{25} 28$

One aspect of an ideal binocular functional VF test that is not clear is what test strategies are most appropriate to use. Of the studies that have previously assessed the VF binocularly, strategies including kinetic, ${ }^{29-33}$ suprathreshold strategies including the 
Esterman VF test, ${ }^{1033-38}$ and threshold tests, ${ }^{24} 3940$ have been used.

The closest current VF tests to a 'gold standard' for assessing functional loss are the binocular Esterman test, $^{41}$ and the integrated visual field (IVF) ${ }^{42}$ although this is a monocular assessment used to produce binocular results. The Esterman test, the only standard binocular field test available, is used to determine the extent of $\mathrm{VF}$ in UK drivers, ${ }^{43}$ although it was not originally designed for this purpose. ${ }^{40}$ Although some studies suggest that the Esterman test is a good predictor of visual function, ${ }^{36445}$ its limitations are well documented and include a substantial ceiling effect which limits the test's applicability for people with low to moderate levels of field loss, 210293738444647 and an inability to differentiate effectively between people with different levels of field loss. ${ }^{38}$ As an alternative, Crabb and Viswanathan ${ }^{42}$ constructed IVF from monocular field plots using software that estimates sensitivities at points of overlapping locations using a 'best location' algorithm. ${ }^{21} 38$ While IVF provide a rapid estimate of a patient's binocular field without extra perimetric examination, ${ }^{21} 23$ they do assume that previous VF results are available which is not always the case in low vision clinics. Binocular function is derived rather than measured, and the plots used usually only assess the central $30^{\circ}$ of $\mathrm{VF}$.

The purpose of this study is to develop an optimal binocular VF test to reflect the functional consequences of VF loss by assessing threshold, suprathreshold and kinetic binocular VF paradigms examining the VF to $60^{\circ}$ eccentricity, and existing standard Esterman and IVF. Results are compared with self-reported difficulty with mobility to determine which VF assessment paradigms best reflect functional difficulty. The VF testing experience of individuals with visual impairment is also considered to help devise optimal strategies for functional field assessment.

\section{METHODS}

Participants with self-reported peripheral VF loss were recruited for this cross-sectional observational study through advertisement of the study with local voluntary agency Cam Sight, and the charities Retinitis Pigmentosa (RP) Fighting Blindness and the International Glaucoma Association. Recruiting participants with a range of ocular conditions allowed the assessment of a range of $\mathrm{VF}$ loss, and reflects the need of a functional field assessment to be applicable to patients with a range of visual disorders. Individuals with conditions not primarily affecting peripheral visual function, such as macular degeneration, were excluded from the study, along with those under 18 years of age and those unable to perform verbal evaluations in English. Ethical approval was granted by Anglia Ruskin University Faculty of Science and Technology Research Ethics committee. All relevant tenets of the Declaration of Helsinki were upheld. All participants gave informed consent after the nature of the study was explained. Participants attended a single session at
Box 1 Thity-five mobility situations from Part 1 of the Independent Mobility Questionnaire IMQ. ${ }^{29} 49$

How difficult is it for you to undertake the following tasks
independently/without assistance (but with the aid of any
mobility aids as required)
1. Walking in familiar areas
2. Walking in unfamiliar areas
3. Moving about: at home
4. Moving about: at work
5. Moving about: in the classroom
6. Moving about: in stores
7. Moving about: outdoors
8. Moving about: in crowded situations
9. Walking at night
10. Using public transportation
11. Detecting ascending stairwells
12. Detecting descending stairwells
13. Walking up steps
14. Walking down steps
15. Stepping onto curbs
16. Stepping off curbs
17. Walking through doorways
18. Walking in high glare areas
19. Adjusting to lighting changed during the day: indoor to outdoor
20. Adjusting to lighting changed during the day: outdoor to indoor
21. Adjusting to lighting changed at night: indoor to streetlights
22. Adjusting to lighting changed at night: streetlights to indoor
23. Walking in dimly lit indoor areas
24. Being aware of another person's presence
25. Avoiding bumping into: people
26. Avoiding bumping into: walls
27. Avoiding bumping into: head height objects
28. Avoiding bumping into: shoulder height objects
29. Avoiding bumping into: waist height objects
30. Avoiding bumping into: knee height objects
31. Avoiding bumping into: low lying objects
32. Avoiding tripping over uneven travel surfaces
33. Moving around in social gatherings
35. Seeing cars at intersec
3. places
3.

the University Eye Clinic, Anglia Ruskin University, with data collected between 3 July 2015 and 4 March 2016 by a single researcher (HS), a qualified optometrist.

Part 1 of the Independent Mobility Questionnaire $(\mathrm{IMQ})^{29} 49$ was used to assess self-perceived ability in mobility. Participants were asked to report if they encountered difficulty in each of 35 mobility situations (Box 1) to obtain a binary response (Yes/No), and then to rate the level the difficulty they experienced on a 5-point Likert scale. Respondents could indicate that a mobility task was not applicable to them, which was scored as missing data.

Participants were also asked to report whether they had fallen in the last 12 months, defined as an event which results in a person coming to rest inadvertently on the ground, floor or other lower level. ${ }^{50}$

High contrast distance visual acuity with habitual distance spectacle correction was assessed binocularly and scored by letter ${ }^{51}$ using a $3 \mathrm{~m}$ internally illuminated Early 
Treatment Diabetic Retinopathy Study (EDTRS) chart. ${ }^{52}$ If the largest letters could not be read at $3 \mathrm{~m}$, the chart was moved $50 \%$ closer to the participant to 1.5 and $0.75 \mathrm{~m}$. Participants with acuity that was not measureable were assigned an acuity of 3.00 logarithm of the minimum angle of resolution (logMAR). ${ }^{53}$ Contrast sensitivity was measured binocularly with habitual distance spectacle correction using a Pelli-Robson Chart ${ }^{54}$ at $1 \mathrm{~m}$ scored on a by letter basis. ${ }^{55}$ Participants with no measurable CS function were assigned a score of 0.00 logarithm of the contrast sensitivity $(\log \mathrm{CS}))^{53}$

Five VF assessments were performed using the Octopus 900 perimeter $^{56}$ and the Humphrey Field Analyser. ${ }^{57}$ $\mathrm{VF}$ test order was randomised, and regular breaks were provided. In all assessments, participants responded to seeing a VF stimulus by pressing a response button. The duration of all assessments was noted. The standard size III Goldmann white stimulus was used throughout. Participants fixated on the standard orange central point target (Humphrey Field Analyser, HFA) or green cross target (Octopus 900). When participants had difficulty seeing the target or maintaining binocular fixation, a $6^{\circ}$ ring target was used on the Octopus, and an adaption to the fixation target on the HFA that slotted into the fixation target hole to provide a black $2 \mathrm{~mm}$ high-contrast pericentral ring around the fixation spot were used.

The three tests conducted on the Octopus 900 perimeter were as follows, using the 'binocular' setting in all cases:

\section{Binocular threshold}

A custom test point pattern was used, assessing the binocular field to $60^{\circ}$ from fixation with 52 points spaced every $7.5^{\circ}$ in the central $30^{\circ}$, and 36 points spaced every $15^{\circ}$ in the peripheral $30^{\circ}-60^{\circ}$. Full aperture trial lenses were used in adult half-eye trial frames with lens centration distances corrected for near for assessment of the central $30^{\circ}$. The peripheral $30^{\circ}-60^{\circ}$ field was assessed without correction to minimise the possibility of lens and frame artefacts. The 'low vision' test strategy was used: stimuli are presented using a 4-2-1 dB bracketing test method starting at $0 \mathrm{~dB}$ (4000asb) in order to arrive quickly at the expected threshold level in subjects with impaired VF. The absolute thresholds achieved at each test location were used to calculate the mean threshold..$^{39} 42$

2. Binocular suprathreshold

The same custom test pattern as for binocular threshold assessment was used. Each point was assessed with a stimulus of $10 \mathrm{~dB}$ intensity. The number of points seen from the total of 88 was used to calculate a percentage score.

3. Binocular kinetic

A white III-4e $(10 \mathrm{~dB})$ target was presented kinetically at an angular velocity of $5^{\circ} / \mathrm{s}$. Vectors were presented from $60^{\circ}$ eccentricity and moved centrally in 12 meridians spaced every $30^{\circ}$. This assessment was completed without refractive correction. The solid angle $\left(\operatorname{deg}^{2}\right)$ subtended by the isopter was determined auto- matically using the Eye Suite software. ${ }^{55}$ The perimeter corrected results for reaction time bias.

The two tests conducted on the HFA were as follows:

1. Integrated monocular threshold fields (IVF)

The central 24-2 threshold test with Swedish interactive thresholding algorithm (SITA)-Fast strategy was used to assess monocular VF. Full aperture trial lenses provided refractive correction. IVF scores were calculated using the best location algorithm. $2123243738424758-60$

2. Esterman

The binocular Esterman VF test examines 120 test points out to $80^{\circ}$ eccentricity using a suprathreshold paradigm with a stimulus intensity of $10 \mathrm{~dB}$. This assessment was completed without refractive correction. The number of points seen was used to calculate the percentage Esterman Efficiency score.

Participants were asked to rank the field tests in order from 1 to 5 based on how acceptable they felt the tests were, and also to rank the perceived usefulness of results presented. Participants were also invited to make further comments relating to acceptability and output of the tests, and qualitative themes were evaluated from this data.

\section{ANALYSIS}

Interval data were derived from the ordinal IMQ responses by the use of Rasch analysis. ${ }^{61}$ The Rasch model, a probabilistic logistic model, is a paradigm for the analysis and scoring of questionnaires that can be used to produce interval level data from ordinal responses, and in turn improves sensitivity to change in function ${ }^{62}$ and correlations with other variables, ${ }^{62} 63$ allows the use of robust parametric statistics on the data, ${ }^{63}$ and provides more accurate measurements of perceived function. ${ }^{64}$ In the Rasch model, items and respondents are scaled according to responses to a group of items. ${ }^{6165}$ The underlying construct being assessed is used to define the relative difficulty of each item. On the same linear scale of the construct, respondents are ordered from least to most ability, and items are ordered from most to least difficult.

Rasch analysis derives person and item measures in logits from raw ordinal data. Person measures are an estimate of a person's underlying ability based on their performance on a set of items that measure a single trait. The item measure is the Rasch estimate of item difficulty.

Person measures were derived using all 35 items, which have been found to constitute a unidimensional scale in people with peripheral field loss due to $\mathrm{RP}^{29}$ and glaucoma. ${ }^{49}$ Higher person measures indicate greater perceived ability.

The reliability indices were assessed in terms of person separation statistics, which provide an indication of the instrument's ability to discriminate between respondents: person separation and person reliability should be greater than the suggested minima of 2.0 and 0.80 , respectively. ${ }^{66}$ Further, item separation statistics provide an indication of how reliably ordered the items are in terms of difficulty: 
item separation and item reliability should be in excess of suggested minima of 3.0 and $0.90{ }^{66}$ Targeting, or the difference between mean item and person measures, should ideally be less than 1.0 logit. ${ }^{6768}$

Additionally, the fit of individual items to a unidimensional construct is assessed. It is considered that items with infit and outfit mean square $(\mathrm{Mn} \mathrm{Sq})$ values within a range of $0.5-1.5$ contribute usefully to a scale.$^{68}$ Items with $\mathrm{Mn}$ Sq values greater than two have the potential to damage the integrity of the scale. ${ }^{69}$

Mann-Whitney $\mathrm{U}$ tests compared visual function in participants who had reported a fall in the previous 12 months and those who had not. Continuous clinical function variables were compared with self-reported mobility function in non-parametric two-tailed Spearman's rho bivariate correlations.

For the binary responses to the 35 mobility tasks of the IMQ, difficulty was compared with different VF test scores using receiver operating characteristic (ROC) analysis to evaluate how effective the tests were at selecting participants with perceived mobility difficulty (sensitivity) and without perceived mobility difficulty (specificity). Sensitivity and specificity were determined for all possible cut-off values for the VF scores and plotted as ROC curves. An area under the ROC curve of 1 indicates a perfect diagnostic procedure, whereas 0.5 indicates a poor procedure. A statistical technique appropriate where two measures are applied to the same set of participants ${ }^{70}$ was used to compare areas under the ROC curves and establish if any VF test was statistically significantly better at predicting perceived difficulty.

\section{RESULTS}

Table 1 shows the characteristics of the 50 participants who were recruited to the study: all completed the study. Sample size is consistent with previous similar studies. ${ }^{123442}$ Person measures for the IMQ are shown. Other parameters derived from the Rasch analysis include person separation of 3.43 (reliability 0.92), indicating that individuals can be reliably ordered by the instrument in terms of their level of perceived ability. Item separation is 2.95 (reliability 0.90), slightly less than the minimum ideal value of 3 , and indicating the instrument might not be able to reliably order items in terms of their difficulty. Targeting $(-1.23 \pm 1.64$ logits $)$ is close to the ideal of within \pm 1 logits of the mean item difficulty. ${ }^{7}$ In terms of item fit, as a representation of how well the questions fitted a unidimensional construct, there were three mis-fitting items with fits in the range 1.5-2.0 Mn Sq. These fits do not diminish the validity of the measures and can be considered acceptable, ${ }^{71}$ and so all items are considered in the analysis. Item fits are also comparable to other Rasch analyses of this instrument, with three items with slight mis-fit also found for samples with $\mathrm{RP}^{29} 72$ and glaucoma. ${ }^{49}$ Reliability statistics indicate adequate VF reliability for the majority of the sample. Fixation losses for the monocular threshold tests suggest reliable results, with only $18 \%$ of participants losing fixation more than $20 \%$ during both assessments. Ninety per cent of false positive and false negative statistics from binocular threshold data were less than $20 \%$. This figure is similar to statistics obtained from Esterman $(86 \%)$ and binocular suprathreshold results $(78 \%)$ results.

Table 2 shows the relationships between the parameters assessed and the outcome measures of self-reported mobility function and fall history. Greater VF loss is significantly associated with greater self-reported difficulty regardless of the method of field assessment, although the relationship is a little weaker for the IVF score. Fifty-six per cent of the sample reported falling at least once in the previous 12 months, but none of the clinical function variables significantly associate with falls history (table 2).

The ability of the VF tests to discriminate between people with and without difficulty with mobility tasks was reasonable (area under the curve $>0.7$ ) for at least one VF test for all except 2 of the 35 questions (figure 1). Statistically significant differences in the areas under the ROC curves were seen (indicated by $*$ in figure 1 ), in that binocular threshold and suprathreshold assessments were better than the IVF at predicting difficulty walking in familiar areas, walking in unfamiliar areas, walking at home, walking in crowded areas, avoiding bumping into knee height objects and finding public toilets. The binocular threshold assessment was also better than the IVF at predicting difficulty avoiding bumping into people, while the Esterman was found to better predict difficulty walking in high glare when compared with the IVF. All three custom tests and the Esterman assessment were better than the IVF at predicting difficulty avoiding bumping into waist height objects, and at predicting difficulty avoiding bumping into low lying objects.

The length of time taken to undertake each VF assessment is shown in figure 2 . The quickest test was the kinetic which took a mean of 1 min $26 \mathrm{~s}( \pm 9 \mathrm{~s})$, while the mean duration of the longest test, the IVF, was 9 min $23 \mathrm{~s}( \pm 24 \mathrm{~s})$.

In terms of the participants' view of how they found the tests to undertake, the most favoured assessment was the kinetic (figure 3), while the IVF was ranked the least favourite test by over $60 \%$ of participants. In addition to ranking the tests, participants also made comments on the different test strategies, and common themes are considered here. Three participants (6\%) commented that shorter tests were preferred, the kinetic assessment in particular. Participants found the kinetic assessment pleasant, less stressful and encouraging, with three participants commenting on being reassured by knowing that a light would be seen eventually. Seven participants (14\%) suggested that the kinetic assessment was more fun and engaging than the static tests, and one remarked on the assessment's novelty value. However, six participants $(12 \%)$ expressed concern that the test was too basic or too short, and that the accuracy of results would be compromised by the test's rapidity. Participants were happy to conduct a longer test if they knew that results would 
Table 1 Descriptive statistics of the variables assessed $(n=50)$

\section{Demographic variables}

\begin{tabular}{|c|c|c|c|}
\hline Gender (n) & \multicolumn{3}{|c|}{29 Males, 21 Females } \\
\hline \multicolumn{4}{|l|}{ Age (years) } \\
\hline Median (25\% IQ-75\% IQ) & \multicolumn{3}{|l|}{$64(55-71)$} \\
\hline \multicolumn{4}{|l|}{ Ocular diagnosis (n) } \\
\hline $\mathrm{RP}$ & \multicolumn{3}{|l|}{14} \\
\hline Retinal detachments/tears & \multicolumn{3}{|l|}{4} \\
\hline Other & \multicolumn{3}{|l|}{9} \\
\hline \multicolumn{4}{|l|}{ Registration status (n) } \\
\hline Registered severely sight impaired & \multicolumn{3}{|l|}{18} \\
\hline Registered sight impaired & \multicolumn{3}{|l|}{8} \\
\hline White cane or guide dog & \multicolumn{3}{|l|}{23} \\
\hline No mobility aids used & \multicolumn{3}{|l|}{27} \\
\hline \multicolumn{4}{|c|}{ Have you been shown your visual field results before? (n) } \\
\hline Yes & \multicolumn{3}{|l|}{36} \\
\hline No & \multicolumn{3}{|l|}{14} \\
\hline \multicolumn{4}{|l|}{ Have you fallen in the previous 12 months? } \\
\hline Yes & \multicolumn{3}{|l|}{28} \\
\hline No & \multicolumn{3}{|l|}{22} \\
\hline Clinical function variables & Mean $( \pm S D)$ & Median (25\% IQ-75\% IQ)) & Range \\
\hline Esterman (\%) & $59.43( \pm 4.81)$ & 67.08 (33.33 to 90.83$)$ & 0.00 to 100.00 \\
\hline Integrated monocular threshold $(\mathrm{dB})$ & $15.69( \pm 1.52)$ & 15.17 (4.88 to 26.48$)$ & 0.90 to 31.96 \\
\hline $\begin{array}{l}\text { Independent Mobility Questionnaire Person } \\
\text { Measures (logits) }\end{array}$ & $-1.23( \pm 0.23)$ & $-1.26(-2.29$ to -0.09$)$ & -5.92 to 1.84 \\
\hline
\end{tabular}

The mean $\pm S D$, and the median (IQR) are given for the clinical visual function variables. *Number of comorbid conditions from a list of 12 common medical conditions representing general health status ${ }^{82}$

$\log C S$, logarithm of the contrast sensitivity; logMAR, logarithm of the minimum angle of resolution; RP, retinitis pigmentosa.

be more beneficial to the practitioner. Eleven participants $(22 \%)$ indicated preference for binocular tests, which were reported as more comfortable and less tiring than monocular assessments. Five participants (10\%) preferred the uniformly bright lights on the binocular suprathreshold assessment; however, four (8\%) found the bright lights at the start of the binocular threshold assessment encouraging.

All participants in the study reported previous experience of VF testing, although $28 \%$ had not seen their VF results before (table 1). All perceived values are being shown their VF. In terms of VF outputs, $48 \%$ of participants preferred the grey scale plots from the binocular threshold analysis, and individuals remarked on the greater level of detail provided on a grey scale plot compared with others. The kinetic plot was most favoured by $37 \%$ of participants, with preference expressed for plots that indicated greater levels of residual field. Four participants commented on the usefulness of having their peripheral field represented, with one participant suggesting that the monocular threshold plots were an inaccurate depiction that overestimated the extent of 
Table 2 Relationship between the variables assessed, and self-reported mobility function and falls history. MannWhitney U values are provided for falls data and Spearman's rho bivariate correlations are provided for the IMQ score

\begin{tabular}{lll}
\hline $\begin{array}{l}\text { Clinical function } \\
\text { variables }\end{array}$ & IMQ score $\left.\mathbf{( R}^{2}\right)$ & $\begin{array}{l}\text { Have you fallen } \\
\text { in the previous }\end{array}$ \\
\hline $\begin{array}{l}\text { Distance visual acuity } \\
\text { (logMAR) }\end{array}$ & $0.31, P \leq 0.001$ & $288.0, P=0.701$ \\
\hline $\begin{array}{l}\text { Contrast sensitivity } \\
\text { (logCS units) }\end{array}$ & $0.33, P \leq 0.001$ & $302.5, P=0.913$ \\
\hline $\begin{array}{l}\text { Binocular threshold (dB) } \\
\text { Binocular }\end{array}$ & $0.47, P \leq 0.001$ & $236.0, P=0.157$ \\
suprathreshold (\%) & $0.47, P \leq 0.001$ & $235.0, P=0.161$ \\
\hline $\begin{array}{l}\text { Binocular kinetic solid } \\
\left.\text { angle (deg }{ }^{2}\right)\end{array}$ & $0.48, P \leq 0.001$ & $236.0, P=0.159$ \\
\hline $\begin{array}{l}\text { Esterman (\%) } \\
\text { IVF (dB) }\end{array}$ & $0.46, P \leq 0.001$ & $209.0, P=0.053$ \\
\hline
\end{tabular}

IVF, integrated visual field; logCS, logarithm of the contrast sensitivity; logMAR, logarithm of the minimum angle of resolution.

their VF. The Esterman output was the least favoured by $38 \%$ of participants. Three participants commented on the size of points on suprathreshold outputs, and expressed difficulty viewing the results.

\section{DISCUSSION}

Five different VF assessments were compared with self-reported difficulty with mobility, in order to determine which VF paradigms are suitable for use as a functional VF assessment. There are four principal findings of this study. First, the paradigm used to assess the VF (threshold or suprathreshold static, or kinetic) makes little difference to the relationship with function: so long as the test is performed binocularly and includes assessment of eccentricities to $60^{\circ}$, the VF outcome measure reflects self-reported mobility function well, in terms of both correlation between VF score and mobility function, and in terms of ability of VF scores to discriminate between individuals who do and do not have difficulty with specific mobility tasks. Second, tests that are quicker to perform (binocular suprathreshold, binocular kinetic, Esterman; figure 2) relate just as well to self-reported mobility function as tests that take longer (binocular threshold; table 1). Functional information is not lost by using kinetic or suprathreshold techniques when compared with the diagnostic gold standard of measuring static thresholds. Third, quicker tests are also more acceptable to patients (figure 3), especially the binocular suprathreshold and kinetic paradigms. Finally, although all participants had experience of $\mathrm{VF}$ assessments, over a quarter did not recall being shown their VF results before. All participants in this study found value in seeing their VF results, and clinicians are encouraged to explain VF results with respect to likely functional difficulties where possible.

A strength of this study is that although some previous studies ${ }^{45}$ 73-75 $^{7}$ have compared different methods of quantifying the VF and their relationship with functional vision, we are not aware of any previous studies that

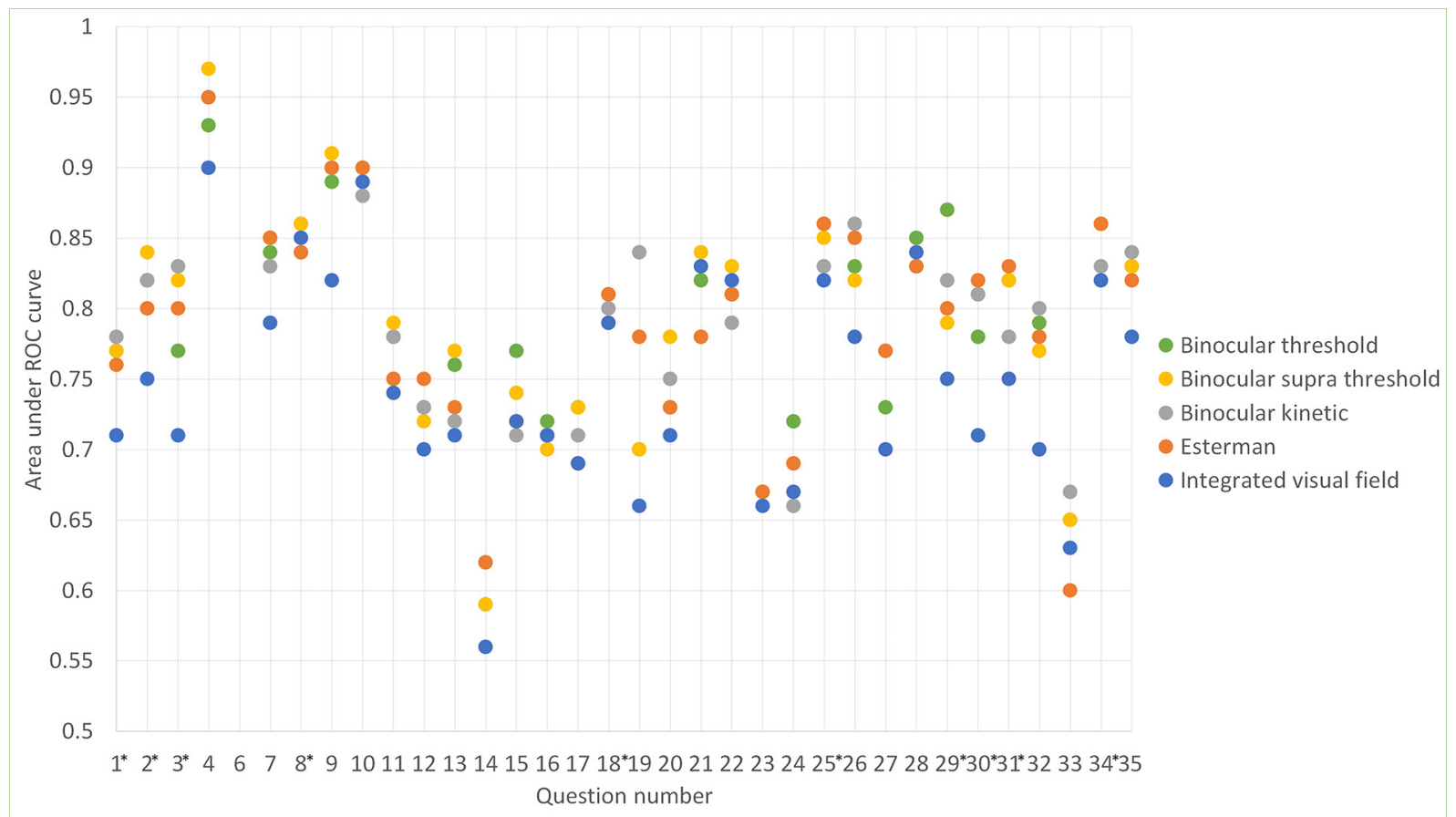

Figure 1 Graphical representation of areas under receiver operating characteristic (ROC) curves for the different visual field tests. The questions to which the numbers on the X-axis refer are given in box 1. Indicates a visual field assessment with a statistically significant greater area under the curve (AUC) than an alternative assessment $(P \leq 0.05)$. All other comparisons were non-significant. 


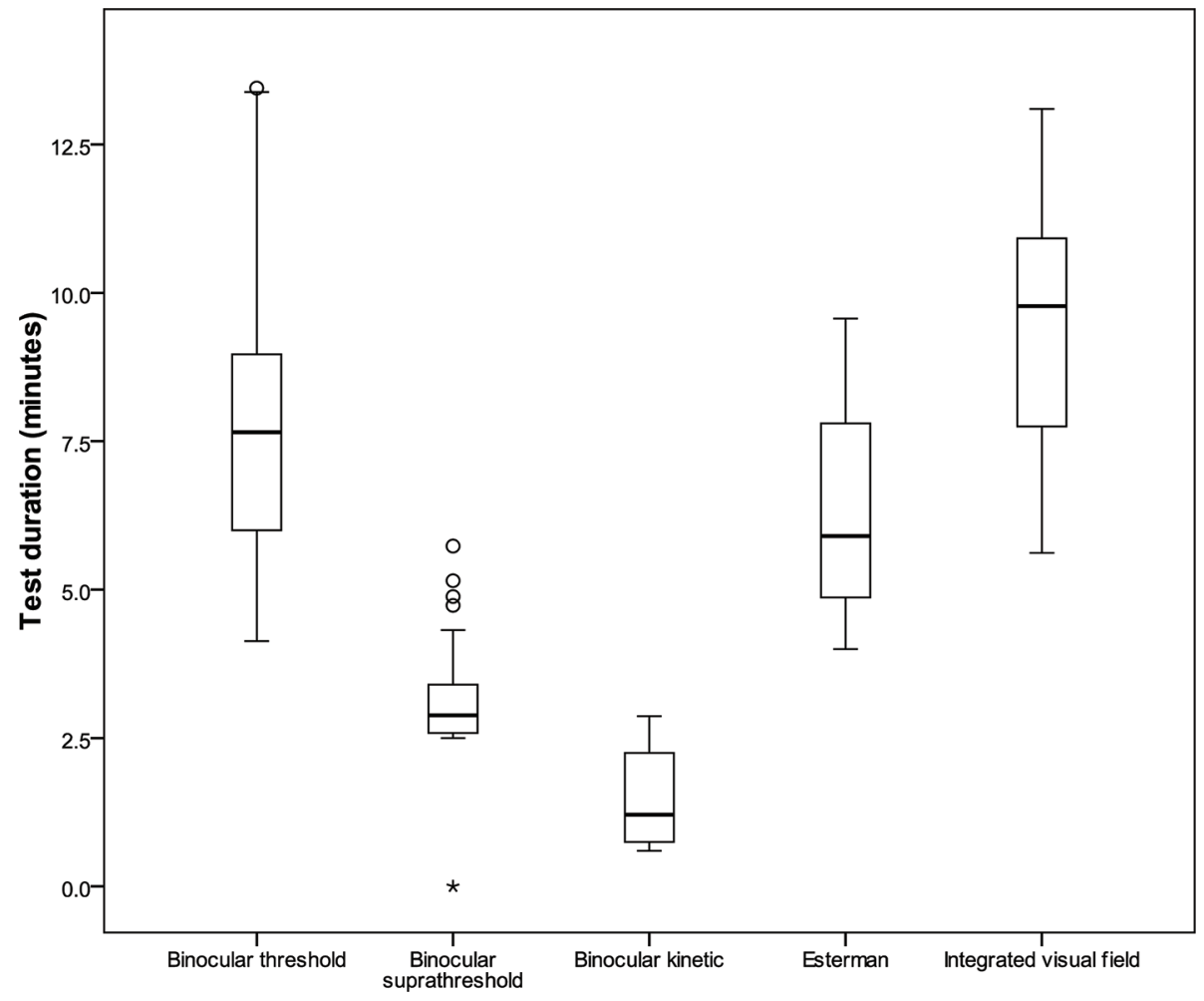

Figure 2 Test durations of each of the five visual field assessments. *indicates an outlier.

have compared different paradigms of VF assessment with functional vision, nor that have taken the patient's perspective into consideration. Rigorous and novel VF testing on a cohort of people with VF loss has been used, along with Rasch analysed data from a validated questionnaire to reflect a broad range of mobility function.

One possible limitation of the study is that we rely on self-report of mobility difficulties rather than directly measuring visual performance on, for example, a mobility circuit. ${ }^{12} 31$ Another potential limitation is that single responses have been used in the kinetic paradigm. Responses to kinetic stimuli can be variable, ${ }^{76}$ and repeated presentations might be necessary to confirm responses, and reduce the impact of outlying responses. ${ }^{77}$

The findings are consistent with previous studies, in that we find that the IVF relates to mobility function. ${ }^{5878}$ Contrary to other studies, however, ${ }^{38}{ }^{42}$ the IVF appears to be less effective at relating to self-related mobility function when compared with the Esterman assessment.

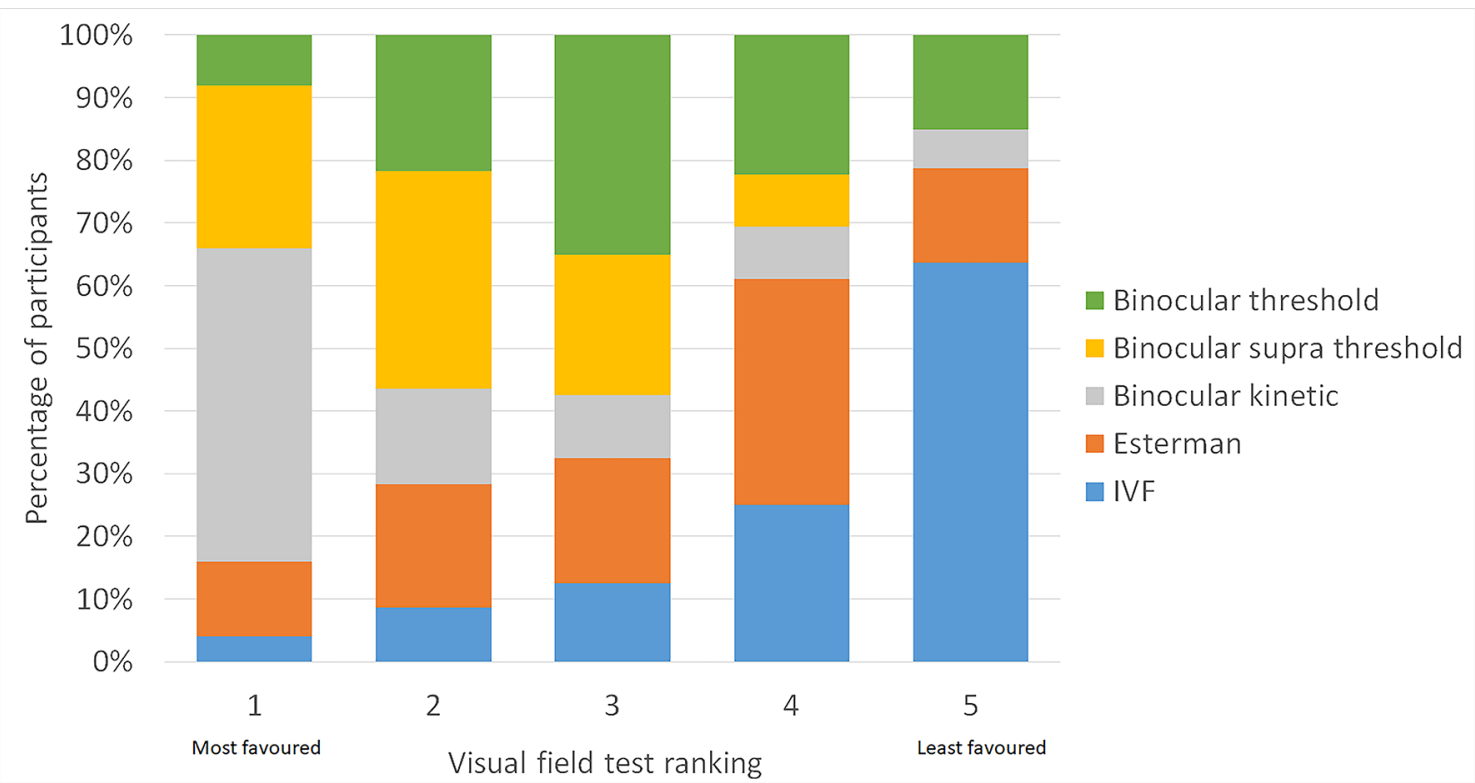

Figure 3 Participants' ranking of visual field tests acceptability. IVF, integrated visual field. 
This may be due to the difference in the degree of VF loss between the sample groups. The average Esterman scores in the current study $(56.4 \%)$ are less than the average scores $\left(87.4 \%{ }^{37}\right.$ and $86.7 \%^{41}$ reported in other studies, and would suggest that the present sample has a greater degree of VF loss. Contrary to some previous studies, no significant correlations were found here between measures of clinical function and fall history. VF loss has been shown to increase the risk of falling in some studies, ${ }^{611}{ }^{13-18}$ but not in others. ${ }^{79} 80$ Variation in findings reflects the multifactorial nature of falls, and also suggests limitations in retrospective reporting of falls. ${ }^{81}$

Participants with a range of ocular conditions affecting peripheral vision (but predominantly glaucoma and RP) and a range of severity of VF loss were used in this study. Results would be expected to be generalisable to people with mild to severe peripheral field loss, but not necessarily to those with visual impairment affecting central visual function, such as macular degeneration.

In conclusion, a binocular $\mathrm{VF}$ test that does not ignore the peripheral $30^{\circ}-60^{\circ}$ of the field is effective for reflecting functional difficulty, regardless of the whether a threshold, suprathreshold or kinetic assessment paradigm is employed. A shorter duration VF test such as the binocular kinetic assessment used in this study is favoured by patients, and this study did not find significantly different effectiveness for this method compared with more time-consuming tests in predicting perceived disability in patients with peripheral field loss. To further explore the potential of a binocular kinetic assessment as a functional field test, future work needs to explore the repeatability of responses, the necessity for repeated presentations, and the assessment's ability to discriminate between individuals with normal and abnormal fields using control subjects.

Contributors All authors made substantial contributions to the design of the work. HS acquired the data for the study. All authors contributed to the analysis and interpretation of the data, drafting the manuscript and critical revision of the article. All authors gave final approval for the manuscript to be published and agree to be accountable for all aspects of the work.

Funding This work was supported by a College of Optometrists' Postgraduate Research Scholarship.

Competing interests None declared.

Ethics approval Anglia Ruskin University Ethics Committee.

Provenance and peer review Not commissioned; externally peer reviewed.

Data sharing statement Data are available from FigShare, doi: 10.6084/ m9.figshare.5484109.v1.

Open Access This is an Open Access article distributed in accordance with the Creative Commons Attribution Non Commercial (CC BY-NC 4.0) license, which permits others to distribute, remix, adapt, build upon this work non-commercially, and license their derivative works on different terms, provided the original work is properly cited and the use is non-commercial. See: http://creativecommons.org/ licenses/by-nc/4.0/

(c) Article author(s) (or their employer(s) unless otherwise stated in the text of the article) 2017. All rights reserved. No commercial use is permitted unless otherwise expressly granted.

\section{REFERENCES}

1. Nelson P, Aspinall P, Papasouliotis O, et al. Quality of life in glaucoma and its relationship with visual function. J Glaucoma 2003;12:139-50.

2. Bibby SA, Maslin ER, Mcllraith R, et al. Vision and self-reported mobility performance in patients with low vision. Clin Exp Optom 2007;90:115-23.

3. Tabrett DR, Latham K. Factors influencing self-reported vision-related activity limitation in the visually impaired. Invest Ophthalmol Vis Sci 2011;52:5293-302.

4. Ramrattan RS, et al. Prevalence and Causes of Visual Field Loss in the Elderly and Associations With Impairment in Daily Functioning. Arch Ophthal 2001;119:1788-94.

5. Sherwood MB, Garcia-Siekavizza A, Meltzer MI, et al. Glaucoma's impact on quality of life and its relation to clinical indicators. A pilot study. Ophthalmology 1998;105:561-6.

6. Ivers RQ, Cumming RG, Mitchell P, et al. Visual impairment and falls in older adults: the Blue Mountains Eye Study. J Am Geriatr Soc 1998;46:58-64.

7. Latham K, Baranian M, Timmis MA, et al. Difficulties With Goals of the Dutch ICF Activity Inventory: Perceptions of Those With Retinitis Pigmentosa and of Those Who Support Them. Investigative Opthalmology \& Visual Science 2015;56:2381-91.

8. Lowe J, Drasdo N. Patients' responses to retinitis pigmentosa. Optom Vis Sci 1992;69:182-5.

9. Szlyk JP, Fishman GA, Grover S, et al. Difficulty in performing everyday activities in patients with juvenile macular dystrophies: comparison with patients with retinitis pigmentosa. $\mathrm{Br} J$ Ophthalmol 1998;82:1372-6.

10. Noe G, Ferraro J, Lamoureux E, et al. Associations between glaucomatous visual field loss and participation in activities of daily living. Clin Exp Ophthalmol 2003;31:482-6.

11. Ramrattan RS, Wolfs RC, Panda-Jonas S, et al. Prevalence and causes of visual field loss in the elderly and associations with impairment in daily functioning: the Rotterdam Study. Arch Ophthalmol 2001;119:1788-94.

12. Lovie-Kitchin JE, Soong GP, Hassan SE, et al. Visual field size criteria for mobility rehabilitation referral. Optom Vis Sci 2010;87:E948-E957.

13. Patino CM, McKean-Cowdin R, Azen SP, et al. Central and peripheral visual impairment and the risk of falls and falls with injury. Ophthalmology 2010;117:199-206.

14. Klein BE, Klein R, Lee KE, et al. Performance-based and selfassessed measures of visual function as related to history of falls, hip fractures, and measured gait time. The Beaver Dam Eye Study. Ophthalmology 1998;105:160-4.

15. Jack Cl, Smith T, Neoh C, et al. Prevalence of low vision in elderly patients admitted to an acute geriatric unit in Liverpool: elderly people who fall are more likely to have low vision. Gerontology 1995;41:280-5.

16. Freeman EE, Muñoz B, Rubin G, et al. Visual field loss increases the risk of falls in older adults: the Salisbury eye evaluation. Invest Ophthalmol Vis Sci 2007;48:4445-50.

17. Klein BE, Moss SE, Klein R, et al. Associations of visual function with physical outcomes and limitations 5 years later in an older population: the Beaver Dam eye study. Ophthalmology 2003;110:644-50.

18. Haymes SA, LeBlanc RP, Nicolela MT, et al. Risk of Falls and Motor Vehicle Collisions in Glaucoma. Investigative Opthalmology \& Visual Science 2007;48:1149-55.

19. McGwin G, Xie A, Mays A, et al. Visual field defects and the risk of motor vehicle collisions among patients with glaucoma. Invest Ophthalmol Vis Sci 2005;46:4437-41.

20. Subhi H, Latham K, Myint J, et al. Functional visual fields: relationship of visual field areas to self-reported function. Ophthalmic Physiol Opt 2017;37:399-408.

21. Nelson-Quigg JM, Cello K, Johnson CA. Predicting binocular visual field sensitivity from monocular visual field results. Invest Ophthalmol Vis Sci 2000;41:2212-21.

22. Schneck ME, Haegerstöm-Portnoy G, Lott LA, et al. Monocular vs. binocular measurement of spatial vision in elders. Optom Vis Sci 2010;87:526-31.

23. Asaoka R, Crabb DP, Yamashita T, et al. Patients have two eyes!: binocular versus better eye visual field indices. Invest Ophthalmol Vis Sci 2011:52:7007-11.

24. Crabb DP, Smith ND, Glen FC, et al. How does glaucoma look?: patient perception of visual field loss. Ophthalmology 2013;120:1120-6.

25. Gardiner SK, Demirel S. Assessment of patient opinions of different clinical tests used in the management of glaucoma. Ophthalmology 2008;115:2127-31. 
26. Glen FC, Baker H, Crabb DP. A qualitative investigation into patients' views on visual field testing for glaucoma monitoring. BMJ Open 2014;4:e003996.

27. Hudson C, Wild JM, O'Neill EC. Fatigue effects during a single session of automated static threshold perimetry. Invest Ophthalmol Vis Sci 1994;35:268-80.

28. Artes P, Monhart M, Marco M. Are big stimuli "easier" to see? An analysis of response times from frequency-of-seeing data. 22nd International Visual Field Imaging Symposium. Udine, Italy, 2016.

29. Turano KA, Rubin GS. Quigley HA Mobility performance in glaucoma. Invest Ophthalmol Vis Sci 1999;40:2803-2309.

30. Lovie-Kitchin JE, Mainstone J, Robinson J, et al. What areas of the visual field are important for mobility in low vision patients? Clin Vis Sci 1990;5:249-63.

31. Haymes SA, Johnston AW, Heyes AD. Relationship between vision impairment and ability to perform activities of daily living. Ophthalmic Physiol Opt 2002;22:79-91.

32. Haymes SA, Leblanc RP, Nicolela MT, et al. Risk of falls and motor vehicle collisions in glaucoma. Invest Ophthalmol Vis Sci 2007;48:1149-55.

33. Hassan SE, Hicks JC, Lei $\mathrm{H}$, et al. What is the minimum field of view required for efficient navigation? Vision Res 2007;47:2115-23.

34. Lee JY, Cho HK, Kee C. Assessment of the Vision-Specific Quality of Life Using Binocular Esterman Visual Field in Glaucoma Patients. Journal of the Korean Ophthalmological Society 2013;54:1567.

35. Mills RP, Drance SM. Esterman disability rating in severe glaucoma. Ophthalmology 1986;93:371-8.

36. Fujita K, Yasuda N, Nakamoto K, et al. [The relationship between difficulty in daily living and binocular visual field in patients with glaucoma]. Nippon Ganka Gakkai Zasshi 2008;112:447-50.

37. Jampel HD. Glaucoma patients' assessment of their visual function and quality of life. Tr Am Ophth Soc 2001;99:301-17.

38. Jampel HD, Friedman DS, Quigley H, et al. Correlation of the binocular visual field with patients' assessment of vision. Inves Ophthal Vis Sci 2002;43:1059-67.

39. Tabrett DR, Latham K. Important areas of the central binocular visual field for daily functioning in the visually impaired. Ophthalmic Physiol Opt 2012;32:156-63.

40. Black A, Lovie-Kitchin JE, Woods RL, et al. Mobility performance with retinitis pigmentosa. Clin Exp Optom 1997;80:1-12.

41. Esterman B. Functional scoring of the binocular field. Ophthalmology 1982;89:1226-34.

42. Crabb DP, Viswanathan AC. Integrated visual fields: a new approach to measuring the binocular field of view and visual disability. Graefes Arch Clin Exp Ophthalmol 2005;243:210-6.

43. Driver and Vehicle Licensing Agency. Visual disorders: assessing fitness to drive. $2016 \mathrm{https}$ ://www.gov.uk/guidance/visual-disordersassessing-fitness-to-drive (accessed Feb 2017)

44. Parrish RK, Gedde SJ, Scott IU, et al. Visual function and quality of life among patients with glaucoma. Arch Ophthalmol 1997;115:1447-55.

45. Choy ES, Mills RP, Drance SM. Automated Esterman testing of disability in glaucoma. In: Greve E, Heiji A, eds. Seventh International Visual Field Symposium. Amsterdam, The Netherlands: Junk Publishers, 1986:527-35.

46. Mills RP. Correlation of quality of life with clinical symptoms and signs at the time of glaucoma diagnosis. Trans Am Ophthalmol Soc 1998:96:753-812.

47. Harris ML, Jacobs NA. Is the Esterman binocular field sensitive enough? In: Mills RP, Wall M, Perimetry update 1994/1995. Amsterdam: Kugler, 1995:13-24.

48. Crabb DP, Viswanathan AC, McNaught Al, et al. Simulating binocular visual field status in glaucoma. Br J Ophthalmol 1998;82:1236-41.

49. Turano KA, Geruschat DR, Baker FH. Fixation behavior while walking: persons with central visual field loss. Vision Res 2002;42:2635-44.

50. Skelton DA, Becker C, Lamb SE, et al. Prevention of Falls Network Europe: a thematic network aimed at introducing good practice in effective falls prevention across Europe. Eur J Ageing 2004;1:89-94.

51. Arditi A, Cagenello R. On the statistical reliability of letter-chart visual acuity measurements. Invest Ophthalmol Vis Sci 1993;34:120-9.

52. Ferris FL, Kassoff A, Bresnick GH, et al. New visual acuity charts for clinical research. Am J Ophthalmol 1982;94:91-6.

53. Myint J, Latham K, Mann D, et al. The relationship between visual function and performance in rifle shooting for athletes with vision impairment. BMJ Open Sport Exerc Med 2016;2:e000080.

54. Pelli DG, Robson JG, Wilkins AJ. The design of a new letter chart for measuring contrast sensitivity. Clin Vis Sci 1988;2:187-99.
55. Elliott DB, Bullimore MA, Bailey IL. Improving the reliability of the Pelli-Robson contrast sensitivity test. Clin Vis $\mathrm{Sci}$ 1991;6:471-5

56. Octopus. Haag-Streit International, AG. Bern, Switzerland.

57. HFA, Carl Zeiss Meditec, Inc. Dublin, CA.

58. Aspinall PA, Johnson ZK, Azuara-Blanco A, et al. Evaluation of quality of life and priorities of patients with glaucoma. Invest Ophthalmol Vis Sci 2008;49:1907-15.

59. Saunders LJ, Russell RA, Crabb DP. Practical landmarks for visual field disability in glaucoma. $\mathrm{Br} J$ Ophthalmol 2012;96:1185-9.

60. Chisholm CM, Rauscher FG, Crabb DC, et al. Assessing visual fields for driving in patients with paracentral scotomata. $\mathrm{Br} \mathrm{J}$ Ophthalmol 2008:92:225-30.

61. Rasch G. Probabalistic models for some intelligence and attainment tests. Chicago: Mesa Press, 1993.

62. Norquist JM, Fitzpatrick R, Dawson J, et al. Comparing alternative Rasch-based methods vs raw scores in measuring change in health. Med Care 2004;42:I-25

63. Khadka J, McAlinden C, Pesudovs K. Quality assessment of ophthalmic questionnaires: review and recommendations. Optom Vis Sci 2013;90:720-44.

64. Stelmack JA, Massof RW. Using the VA LV VFQ-48 and LV VFQ-20 in low vision rehabilitation. Optom Vis Sci 2007;84:705-9.

65. Reise SP, Henson JM. A discussion of modern versus traditional psychometrics as applied to personality assessment scales. $J$ Pers Assess 2003;81:93-103.

66. Linacre JM. Reliability and separation of measures. http://www. winsteps.com/winman/reliability.htm (retrieved 30 Jun 2015).

67. Gothwal VK, Wright TA, Lamoureux EL, et al. Rasch analysis of visual function and quality of life questionnaires. Optom Vis Sci 2009;86:1160-8.

68. Marella M, Gothwal VK, Pesudovs K, et al. Validation of the Visual Disability Questionnaire (VDQ) in India. Optom Vis Sci 2009;86:E826-E835.

69. Wright B, Linacre JM. Reasonable mean-square fit values. www. rasch.org/rmt/rmt83b.htm (retrieved 29 Feb 2016).

70. DeLong ER, DeLong DM, Clarke-Pearson DL. Comparing the areas under two or more correlated receiver operating characteristic curves: a nonparametric approach. Biometrics 1988:44:837-45.

71. Linacre JM. Dimensionality investigation - an example. http://www. winsteps.com/winman/multidimensionality.htm. (retrieved 12 Nov 2014).

72. Fenwick EK, O'Hare F, Deverell L, et al. Rasch Analysis of the Independent Mobility Questionnaire. Optom Vis Sci 2016;93:181-7.

73. Haymes S, Guest D, Heyes A, et al. Mobility of people with retinitis pigmentosa as a function of vision and psychological variables. Optom Vis Sci 1996;73:621-37.

74. Safran AB, Glaser JS. Statokinetic dissociation in lesions of the anterior visual pathways. A reappraisal of the Riddoch phenomenon Arch Ophthalmol 1980;98:291-5.

75. Yanagisawa M, Kato S, Kunimatsu S, et al. Relationship between vision-related quality of life in Japanese patients and methods for evaluating visual field. Jpn J Ophthalmol 2011;55:132-7.

76. Lynn J, Swanson W, Fellman R. Evaluation of automated kinetic perimetry (AKP) with the Humphrey Field Analyzer. Perimetry Update 1991:433-52

77. Mönter VM, Crabb DP, Artes PH. Reclaiming the Periphery: Automated Kinetic Perimetry for Measuring Peripheral Visual Fields in Patients With Glaucoma. Invest Ophthalmol Vis Sci 2017:58:868-75.

78. Black AA, Wood JM, Lovie-Kitchin JE. Inferior field loss increases rate of falls in older adults with glaucoma. Optom Vis $\mathrm{Sci}$ 2011;88:1275-82.

79. Friedman SM, Munoz B, West SK, et al. Falls and fear of falling: which comes first? A longitudinal prediction model suggests strategies for primary and secondary prevention. J Am Geriatr Soc 2002;50:1329-35.

80. Glynn RJ, Seddon JM, Krug JH, et al. Falls in elderly patients with glaucoma. Arch Ophthalmol 1991;109:205-10.

81. Cummings SR, Nevitt MC, Kidd S. Forgetting falls. The limited accuracy of recall of falls in the elderly. J Am Geriatr Soc 1988;36:613-6.

82. van Nispen RMA, Hoeijmakers JGJ, de Boer MR, et al. Agreement Between Self-Reported Co-morbidity of Visually Impaired Older Patients and Reports from their General Practitioners. Vis Impair Res 2008;10:49-56. 